\title{
O DIREITO AO TRABALHO POR PARTE DAS PESSOAS COM DEFICIÊNCIA NO SERVIÇO PÚBLICO
}

\section{THE RIGHT TO WORK BY THE PERSONS WITH DISABILITIES IN THE PUBLIC SPHERE}

${ }^{1}$ Milena Sousa de Oliveira

\section{RESUMO}

A luta pelos direitos, e suas respectivas garantias, travada pelas pessoas com deficiência representa uma verdadeira batalha democrática, na medida em que se trata de uma minoria cada vez mais crescente no mundo. As conquistas alcançadas por essa minoria ganhou, de início, expressão internacional e posteriormente adesão nacional, culminando com a assinatura da Convenção de Nova Iorque, de 2008. Com efeito, o desdobramento da igualdade tratar iguais igualmente e desiguais, desigualmente restaria esvaziado de sentido, se não houvesse identificação de quem são os desiguais e em que consistem suas desigualdades, a fim de que estas possam ser superadas. Um dos principais meios de se atingir essa igualdade é por meio da proteção do direito ao trabalho dessas pessoas, inclusive no âmbito público. Trabalhar é o exercício produtivo da cidadania e como tal não pode ser obstado nem diminuído em razão da deficiência. Trabalhar no serviço público, para as pessoas com deficiência, era um desafio que foi vencido apenas parcialmente. Apesar de o acesso aos cargos públicos já ser assegurado às pessoas com deficiência, por meio da reserva de vaga, resta agora proteger e implementar o exercício efetivo das respectivas atribuições. O objetivo deste artigo é expor a evolução da legislação nacional e internacional, a fim de demonstrar a atual vertente inclusiva que deve ser seguida quando se pretende implementar direitos das pessoas com deficiência. Após breve investigação do instrumental legislativo do qual as pessoas com deficiência dispõem em seu favor, seguir-se-á a minudente investigação da legislação interna, estadual e federal, a fim de identificar a presença, ou não, de institutos jurídicos que proporcionem a adaptação ou readaptação do servidor com deficiência às funções do cargo no qual foi investido, com críticas a este instituto, quando utilizado como forma de exclusão da pessoa com deficiência.

Palavras-chave: Pessoas com deficiência, Democracia, Igualdade, Direito ao trabalho, Serviço público, Exercício atribuições cargo

1 Graduação em Direito pela Universidade Federal do Ceará - UFC, Ceará (Brasil). E-mail: milenasousaoliveira@gmail.com 


\begin{abstract}
The strugles lived by the persons with disabilities on their quest for attaining their proper rights have taken the shape of a true democratic battle with the increasing number of persons in this situation and the uprise in their worldwide influence. The advances reached by this minority group have drawn, at first, international attention and, subsequently, national acceptance, leading to the signature of the New York Covention, in 2008. In fact, the equality principle treating the equals equally and the unequals unequally - looses its meaning without the defiinition of what are these inequalities and who are the people who suffer from it. One of the main approaches for achieving equality is by protecting these people's right to work, inclusive within the public sphere. Work a productive act of citizenship and, as such, cannot be denied or limited due to the disability. For the persons with disabilities, working in the public service is a challenge which has been only partially solved. Although their access to jobs in the public service has been widely guaranteed, it is still necessary to ensure the essential conditions for the effective accomplishment of their assigned duties. The main goal of this paper is to analize the evolution of the national and international law in terms of the current understanding that implementing the rights of people with disabilities should be centered on inclusion. After a brief investigation of the legislation protecting the rights of the people with disabilities, we make a detailed study of the internal, State and Federal Law in order to identify the presence or absence of regulations that promote the adaptation or readaptation of workers with disabilities. The analysis will be focused on the comparison between the worker's attained post and his/hers actual duties and the responsabilities, specially in the cases on which the readaptation process act in terms of promoting the exclusion of the person with disability.
\end{abstract}

Keywords: Persons with disabilities, Democracy, Equality, Right to work, Public service, Accomplishment assigned duties 


\section{INTRODUÇÃo}

$\mathrm{O}$ estudo dos direitos das pessoas com deficiência proporciona àqueles que sobre eles se debruçam a experiência da verdadeira luta das minorias no Brasil.

Os direitos humanos das pessoas com deficiência experimentaram, em sua evolução, desde a completa intolerância, em que a deficiência era concebida como impureza ou castigo, passando por uma fase seguinte, identificada com o modelo médico, como se a deficiência fosse algo a ser curado, para que, lograssem figurar nos tratados e convenções internacionais, e, por fim, no mais alto patamar da hierarquia normativa nacional.

Um dos principais vetores de inclusão social das pessoas com deficiência é o direito ao trabalho. Com efeito, trabalhar é o exercício produtivo da cidadania, integrando o homem ao meio social ao qual pertence, agregando-lhe valor para além do econômico. Trata- se, ao mesmo tempo, de fundamento da República Federativa do Brasil e de direito social ${ }^{1}$. Muito mais do que um dever, consiste em direito inerente à dignidade humana, ao qual somente se admite restrições em circunstâncias excepcionalíssimas. Nascer com deficiência ou adquiri-la no decorrer da vida, não deve ser fator discriminante que autorize a restrição do direito ao trabalho.

A Convenção de Nova Iorque, cujas normas foram alçadas ao patamar de normas constitucionais, por meio do procedimento de aprovação previsto no artigo $5^{\circ}, \S 3^{\circ 2}$ da Constituição Federal, reconhece o direito das pessoas com deficiência ao trabalho, em igualdade de oportunidades com as demais pessoas. Com vistas a promover esse direito, os Estados Partes devem assegura-lo às pessoas com deficiência, inclusive àquelas que tiverem adquirido uma deficiência no emprego, adotando medidas apropriadas, incluídas na legislação, com o fim de, entre outros de (artigo 27, alínea “g”) empregar pessoas com deficiência no setor público.

A Constituição Federal, arrimada no princípio da igualdade material, promove a primeira medida afirmativa no sentido de determinar a reserva de vagas em seu artigo 37 ,

1 Constituição Federal de 1988. Art. $1^{\text {o }}$ A República Federativa do Brasil, formada pela união indissolúvel dos Estados e Municípios e do Distrito Federal, constitui-se em Estado Democrático de Direito e tem como fundamentos: (...) IV - os valores sociais do trabalho e da livre iniciativa;

Art. $6^{\circ}$ São direitos sociais a educação, a saúde, a alimentação, o trabalho, a moradia, o lazer, a segurança, a previdência social, a proteção à maternidade e à infância, a assistência aos desamparados, na forma desta Constituição. (Redação dada pela Emenda Constitucional n ${ }^{\circ}$ 64, de 2010)

$2 \S 3^{\circ}$ Os tratados e convenções internacionais sobre direitos humanos que forem aprovados, em cada Casa do Congresso Nacional, em dois turnos, por três quintos dos votos dos respectivos membros, serão equivalentes às emendas constitucionais. (Incluído pela Emenda Constitucional nº 45, de 2004) 
inciso VIII, o qual se encontra associado diretamente ao direito de acesso aos cargos públicos e à investidura via concurso público, consignados nos incisos I e II do mesmo artigo.

Tendo por base a Convenção de Nova Iorque, foi recentemente aprovada a Lei $\mathrm{n}^{\circ}$ 13.146 de 6 de julho de 2015, a Lei Brasileira de Inclusão da Pessoa com Deficiência, cujos artigos 34 e 35 asseguram o direito ao trabalho, em ambiente acessível e inclusivo, em igualdade de oportunidades com as demais pessoas, impondo às pessoas jurídicas de direito público a garantia desse direito às pessoas com deficiência.

No entanto, direito ao trabalho, no âmbito público significa - para além do acesso ao cargo público, viabilizado mediante a reserva de vaga - o exercício efetivo das funções inerentes ao cargo. Muito embora a previsão da reserva legal de vagas represente uma vitória das pessoas com deficiência contra a abissal desvantagem em que concorriam nos concursos públicos, ela não serve para lhes assegurar o próximo passo dentro do serviço público. Hoje, a pessoa com deficiência ingressa na instituição pública de maneira isonômica em relação aos demais. Há lei lhes assegurando esse direito. Todavia, o ordenamento brasileiro parece ressentirse do instrumental normativo que busque tutelar, de fato, o exercício pleno das atribuições legais por parte das pessoas com deficiência investidas em cargo público.

Assim, cumpre indagar: o direito das pessoas com deficiência, aprovadas em concurso público, ao pleno exercício das atribuições legais inerentes ao cargo encontra-se devidamente albergado pelo ordenamento jurídico brasileiro? A Administração Pública dispõe da estrutura necessária a viabilizar esse direito às pessoas com deficiência? Até que ponto as adaptações e reabilitações comprometem o exercício do cargo, desvirtuando-o de suas reais finalidades? Como proceder em casos de deficiência superveniente à investidura no cargo público?

Com o escopo de traçar os limites metodológicos da presente questão, será necessário situá-la no debate atual entre a democracia e os direitos das minorias, ressaltando a importância do princípio da igualdade como ferramenta adequada para se atingir os ideais de justiça social.

Em seguida, delimitar-se-á o conceito de pessoa com deficiência e a importância de conhecer a denominação mais adequada para o sujeito do direito aqui estudado. Necessário ainda, para que se possa visualizar a exata extensão do problema no âmbito nacional, o estudo da a realidade atual da pessoa com deficiência no brasil e como se deu a evolução da proteção de seus direitos. 
Fixadas as premissas necessárias à compreensão do problema, alcançar-se-á o cerne da presente pesquisa, qual seja, o direito ao trabalho por parte das pessoas com deficiência, especificamente quanto ao acesso ao cargo público e seu efetivo exercício.

\section{A DEMOCRACIA E O DIREITO DAS MINORIAS}

A República Federativa do Brasil, formada pela união indissolúvel dos Estados e Municípios e do Distrito Federal, constitui-se em Estado Democrático de Direito. É este o texto do preceptivo inaugural da Constituição Federal de 1988.

Democracia significa - desde suas raízes históricas, fixadas nas cidades-estado da Grécia Antiga - governo da maioria. Desde então, a prática da democracia, aperfeiçoada principalmente durante o século $\mathrm{XX}$, passou a lançar mão de instrumentos modernos de legitimação de poder, tais como o sufrágio universal, a alternância de poder, organização de partidos políticos, dentre outros (OLIVEIRA, 2006, p. 1).

No entanto, apesar de toda a evolução pragmática absorvida também pela atual Carta Política nacional, a democracia andará longe de concretizar os fundamentos da República Federativa do Brasil - previstos no mesmo preceptivo constitucional supracitado, dentre os quais a dignidade da pessoa humana - caso seja compreendida apenas como o governo da maioria.

A vontade da maioria do povo pode estar tão longe dos ideais de justiça quanto a vontade de um ditador qualquer, ainda que, à primeira vista, pareça inconcebível tal afirmação (BAPTISTA, 2003, p. 196). Dessa constatação, surge a necessidade de assegurar os direitos das minorias e dotá-las de instrumentos capazes de efetivá-los, a fim de que a democracia passe a ser, além de regime político, um caminho para que a sociedade atinja seus ideais de justiça.

A aparente tautologia existente na expressão Estado Democrático de Direito ${ }^{3}$ foi superada, no âmbito da política moderna, a partir dos ideais revolucionários de liberdade, igualdade e fraternidade. Com efeito, analisando a Declaração dos Direitos do Homem e do

3 Tautologia, no sentido de que a democracia, em primeira análise, significa o governo da maioria e, se assim o é, certas instituições, como a própria Constituição, que assegura direitos às minorias, seriam, em última instância, contramajoritárias. A respeito ver debate sobre o tema entre Michelman e Habermas em OLIVEIRA, 2006, p. 3. 
Cidadão, de 1789, reconhece-se a marca das duas grandes tradições do pensamento político moderno, a liberal e a republicana (OLIVEIRA, 2006, p. 3).

Se é verdade que as liberdades públicas são as principais garantias para se exercitar uma democracia em que os direitos individuais se sobrepõem ao do Estado, também o é que elas não são suficientes para que esta mesma democracia seja instrumental de justiça. Para Bobbio (1997, p. 20), estado liberal e estado democrático são interdependentes em dois modos: na direção que vai do liberalismo à democracia, no sentido de que são necessárias certas liberdades para o exercício correto do poder democrático, e na direção oposta que vai da democracia ao liberalismo, no sentido de que é necessário o poder democrático para garantir a existência e a persistência das liberdades fundamentais.

Nesse contexto, muito além de simples conceito de regime político, a democracia passa a encerrar a noção mais abrangente de Estado social liberal. A esse respeito, arremata Bobbio (1997, p. 112): “A passagem do estado liberal para o estado social é assinalada pela passagem de um direito com função predominantemente protetora repressiva para um direito cada vez sempre mais promocional. [...] Para que uma sociedade qualquer permaneça reunida, é preciso que se introduza também algum critério de justiça distributiva".

Com efeito, um "direito cada vez mais promocional" e a introdução de "algum critério de justiça distributiva, são alcançados pelo Estado e pela sociedade quando se lança mão do segundo valor da trilogia revolucionária francesa: a igualdade. Esse direito de ser igual necessita, porém, alcançar as desigualdades de fato e, para que isso ocorra efetivamente, exige que se concretizem os devidos acertos (GURGEL, 2006, p. 46).

Por fim, para completar o tripé dos axiomas revolucionários, a fraternidade, sob o prisma da democracia, representa o respeito pelo outro, a almejada tolerância das diferenças, cenário em que convivem harmoniosamente as maiorias e as minorias sociais. É exatamente nesse ponto em que se situa a importância da investigação cuidadosa dos direitos dessas minorias, considerando seu histórico marcado pela luta contra as mais diversas formas de discriminação, o qual não deve, por outro lado, servir de fundamento para amparar políticas paternalistas, alienantes, muito mais excludentes do que inclusivas. 


\section{O PRINCÍPIO DA IGUALDADE - FERRAMENTA ADEQUADA PARA SE ATINGIR OS IDEAIS DE JUSTIÇA SOCIAL}

Conforme Piovesan (2013, p. 270), a Convenção de Nova Iorque contempla as vertentes repressiva (atinente à proibição da discriminação) e promocional (atinente à promoção da igualdade), no que tange à proteção dos direitos das pessoas com deficiência. Expressamente enuncia a possibilidade dos Estados adotarem medidas especiais necessárias a acelerar ou alcançar a igualdade de fato das pessoas com deficiência (artigo $5^{\circ}$, parágrafo $4^{\circ}$ ).

A Convenção de Nova Iorque, portanto, toca novamente no objetivo primordial de toda norma cuja pretensão esteja inserida no contexto descrito por Bobbio (1997, p.112), de passagem do estado liberal para o estado social, do direito com função predominantemente protetora repressiva para um direito promocional. Trata-se da igualdade de fato, da qual o Estado deve lançar mão para assegurar às minorias - no caso, as pessoas com deficiência - a efetiva concretização de seus direitos fundamentais.

A propósito, assegura o artigo $5^{\circ}$. da Constituição de 1988 , todos são iguais perante a lei, sem distinção de qualquer natureza. No mesmo preceptivo, garante-se aos brasileiros e aos estrangeiros residentes no País a inviolabilidade do direito à igualdade, além da proteção ao direito à vida, à liberdade, à segurança e à propriedade. Eis a pedra angular da concretização da inclusão social de todas as pessoas com deficiência.

Cumpre, neste ponto, destacar o significado das duas expressões de igualdade mencionadas pelo texto constitucional. A igualdade formal "perante" a lei compõe, juntamente com a igualdade "na" lei, o conteúdo axiológico do princípio constitucional da igualdade, contrapondo-se, um ao outro, à medida que se complementam. Segundo José Afonso da Silva (2003, p. 218), a igualdade formal “corresponde à obrigação de aplicar as normas jurídicas gerais aos casos concretos, na conformidade com o que elas estabelecem, mesmo se delas resultar uma discriminação, o que caracteriza a isonomia puramente formal, enquanto a igualdade 'na' lei exige que, nas normas jurídicas, não haja distinções que não sejam autorizadas pela própria constituição. Enfim, segundo essa doutrina, a igualdade 'perante' a lei seria uma exigência feita a todos aqueles que aplicam as normas jurídicas gerais aos casos concretos, ao passo que a igualdade 'na' é uma exigência dirigida tanto àqueles que criam as normas jurídicas gerais como àqueles que as aplicam aos casos concretos”. 
O comezinho desdobramento da igualdade - tratar iguais igualmente e desiguais, desigualmente - mostra-se aprioristicamente vazio de sentido, se não houver identificação de quem são os desiguais e em que consistem suas desigualdades. Por essa razão, Celso Antônio Bandeira de Mello (1978, p. 47) afirma ser possível, e até recomendável, desigualar ou tratar desigualmente situações em que haja correlação lógica entre o fator de discrímen e a desequiparação protegida.

Partindo dessa premissa, leciona Araújo (2011, p. 83) que a igualdade formal deve ser quebrada diante de situações que logicamente autorizam tal ruptura. Assim é razoável entender-se que a pessoa com deficiência tem, pela sua própria condição, direito à quebra da igualdade, em situações das quais participe com pessoas sem deficiência.

A correta compreensão da aparente dicotomia entre o princípio da igualdade de todos perante a lei o tratamento constitucional diferenciado às pessoas com deficiência é determinante para a eficácia e aplicabilidade das normas que lhe são dirigidas. Este tratamento diferenciado consiste em assegurar às pessoas com deficiência, entre outros direitos de ordem social previstos pela Convenção de Nova Iorque, o direito à vida independente e inclusão na comunidade (artigo 19) ${ }^{4}$, direito à educação (artigo 24) ${ }^{5}$, habilitação e reabilitação (artigo 26) ${ }^{6}$ e ao trabalho (artigo 27$)^{7}$.

Art. 19. Vida independente e inclusão na comunidade

Os Estados Partes desta Convenção reconhecem o igual direito de todas as pessoas com deficiência de viver na comunidade, com a mesma liberdade de escolha que as demais pessoas, e tomarão medidas efetivas e apropriadas para facilitar às pessoas com deficiência o pleno gozo desse direito e sua plena inclusão e participação na comunidade, inclusive assegurando que:

a) As pessoas com deficiência possam escolher seu local de residência e onde e com quem morar, em igualdade de oportunidades com as demais pessoas, e que não sejam obrigadas a viver em determinado tipo de moradia;

b) As pessoas com deficiência tenham acesso a uma variedade de serviços de apoio em domicílio ou em instituições residenciais ou a outros serviços comunitários de apoio, inclusive os serviços de atendentes pessoais que forem necessários como apoio para que as pessoas com deficiência vivam e sejam incluídas na comunidade e para evitar que fiquem isoladas ou segregadas da comunidade;

c) Os serviços e instalações da comunidade para a população em geral estejam disponíveis às pessoas com deficiência, em igualdade de oportunidades, e atendam às suas necessidades.

5 Art. 24. Educação 1.Os Estados Partes reconhecem o direito das pessoas com deficiência à educação. Para efetivar esse direito sem discriminação e com base na igualdade de oportunidades, os Estados Partes assegurarão sistema educacional inclusivo em todos os níveis, bem como o aprendizado ao longo de toda a vida, com os seguintes objetivos:

a) O pleno desenvolvimento do potencial humano e do senso de dignidade e auto-estima, além do fortalecimento do respeito pelos direitos humanos, pelas liberdades fundamentais e pela diversidade humana;

b) O máximo desenvolvimento possível da personalidade e dos talentos e da criatividade das pessoas com deficiência, assim como de suas habilidades físicas e intelectuais;

c) A participação efetiva das pessoas com deficiência em uma sociedade livre.

2.Para a realização desse direito, os Estados Partes assegurarão que: 
a) As pessoas com deficiência não sejam excluídas do sistema educacional geral sob alegação de deficiência e que as crianças com deficiência não sejam excluídas do ensino primário gratuito e compulsório ou do ensino secundário, sob alegação de deficiência;

b) As pessoas com deficiência possam ter acesso ao ensino primário inclusivo, de qualidade e gratuito, e ao ensino secundário, em igualdade de condições com as demais pessoas na comunidade em que vivem;

c) Adaptações razoáveis de acordo com as necessidades individuais sejam providenciadas;

d) As pessoas com deficiência recebam o apoio necessário, no âmbito do sistema educacional geral, com vistas a facilitar sua efetiva educação;

e) Medidas de apoio individualizadas e efetivas sejam adotadas em ambientes que maximizem o desenvolvimento acadêmico e social, de acordo com a meta de inclusão plena.

3.Os Estados Partes assegurarão às pessoas com deficiência a possibilidade de adquirir as competências práticas e sociais necessárias de modo a facilitar às pessoas com deficiência sua plena e igual participação no sistema de ensino e na vida em comunidade. Para tanto, os Estados Partes tomarão medidas apropriadas, incluindo:

a) Facilitação do aprendizado do braille, escrita alternativa, modos, meios e formatos de comunicação aumentativa e alternativa, e habilidades de orientação e mobilidade, além de facilitação do apoio e aconselhamento de pares;

b) Facilitação do aprendizado da língua de sinais e promoção da identidade lingüística da comunidade surda;

c) Garantia de que a educação de pessoas, em particular crianças cegas, surdocegas e surdas, seja ministrada nas línguas e nos modos e meios de comunicação mais adequados ao indivíduo e em ambientes que favoreçam ao máximo seu desenvolvimento acadêmico e social.

4.A fim de contribuir para o exercício desse direito, os Estados Partes tomarão medidas apropriadas para empregar professores, inclusive professores com deficiência, habilitados para o ensino da língua de sinais e/ou do braille, e para capacitar profissionais e equipes atuantes em todos os níveis de ensino. Essa capacitação incorporará a conscientização da deficiência e a utilização de modos, meios e formatos apropriados de comunicação aumentativa e alternativa, e técnicas e materiais pedagógicos, como apoios para pessoas com deficiência.

5.Os Estados Partes assegurarão que as pessoas com deficiência possam ter acesso ao ensino superior em geral, treinamento profissional de acordo com sua vocação, educação para adultos e formação continuada, sem discriminação e em igualdade de condições. Para tanto, os Estados Partes assegurarão a provisão de adaptações razoáveis para pessoas com deficiência.

6 Art. 26. Habilitação e reabilitação.

1.Os Estados Partes tomarão medidas efetivas e apropriadas, inclusive mediante apoio dos pares, para possibilitar que as pessoas com deficiência conquistem e conservem o máximo de autonomia e plena capacidade física, mental, social e profissional, bem como plena inclusão e participação em todos os aspectos da vida. Para tanto, os Estados Partes organizarão, fortalecerão e ampliarão serviços e programas completos de habilitação e reabilitação, particularmente nas áreas de saúde, emprego, educação e serviços sociais, de modo que esses serviços e programas:

a) Comecem no estágio mais precoce possível e sejam baseados em avaliação multidisciplinar das necessidades e pontos fortes de cada pessoa;

b) Apóiem a participação e a inclusão na comunidade e em todos os aspectos da vida social, sejam oferecidos voluntariamente e estejam disponíveis às pessoas com deficiência o mais próximo possível de suas comunidades, inclusive na zona rural.

2.Os Estados Partes promoverão o desenvolvimento da capacitação inicial e continuada de profissionais e de equipes que atuam nos serviços de habilitação e reabilitação.

3.Os Estados Partes promoverão a disponibilidade, o conhecimento e o uso de dispositivos e tecnologias assistivas, projetados para pessoas com deficiência e relacionados com a habilitação e a reabilitação.

$7 \quad$ Art. 27. Trabalho e emprego. 1.Os Estados Partes reconhecem o direito das pessoas com deficiência ao trabalho, em igualdade de oportunidades com as demais pessoas. Esse direito abrange o direito à oportunidade de se manter com um trabalho de sua livre escolha ou aceitação no mercado laboral, em ambiente de trabalho que seja aberto, inclusivo e acessível a pessoas com deficiência. Os Estados Partes salvaguardarão e promoverão a realização do direito ao trabalho, inclusive daqueles que tiverem adquirido uma deficiência no emprego, adotando medidas apropriadas, incluídas na legislação, com o fim de, entre outros:

a) Proibir a discriminação baseada na deficiência com respeito a todas as questões relacionadas com as formas de emprego, inclusive condições de recrutamento, contratação e admissão, permanência no emprego, ascensão profissional e condições seguras e salubres de trabalho; 


\section{DEFICIÊNCIA - CONCEITO E TERMINOLOGIA ADEQUADA}

A deficiência no ser humano, em todas as suas variáveis, é fator indiscutível de segregação social, inserindo os indivíduos que com ela convivem num desses grupos minoritários para os quais o Estado deve voltar sua atenção, sob pena de comprometer o princípio democrático.

O conceito de deficiência pode ser alcançado sob o prisma das diferentes formas de tratamento que lhe foram dedicadas durante a história. A partir dessa perspectiva, pode-se enumerar o modelo médico ou individual, o modelo social, o modelo das minorias e o modelo cultural ou estatal (SOUZA, p. 59).

O primeiro deles enuncia que deficiência seria a apresentação orgânica de um estado patológico de vida ou perturbações orgânicas. O modelo social indica que não se trata de moléstia individual, mas dificuldades resultantes das condições sociais a que o sujeito se encontra submetido. Conferindo maior ênfase à imagem de grupo, o modelo de minorias concebe a deficiência como um nicho social, marginalizado, no qual também se encontram outras minorias, segregadas em função da cor, gênero etc. Por fim, o modelo cultural revela uma maior preocupação com os critérios legais, regulamentos estatais e processos concessivos de políticas públicas assistenciais (SOUZA, p. 66).

b) Proteger os direitos das pessoas com deficiência, em condições de igualdade com as demais pessoas, às condições justas e favoráveis de trabalho, incluindo iguais oportunidades e igual remuneração por trabalho de igual valor, condições seguras e salubres de trabalho, além de reparação de injustiças e proteção contra o assédio no trabalho;

c) Assegurar que as pessoas com deficiência possam exercer seus direitos trabalhistas e sindicais, em condições de igualdade com as demais pessoas;

d) Possibilitar às pessoas com deficiência o acesso efetivo a programas de orientação técnica e profissional e a serviços de colocação no trabalho e de treinamento profissional e continuado;

e) Promover oportunidades de emprego e ascensão profissional para pessoas com deficiência no mercado de trabalho, bem como assistência na procura, obtenção e manutenção do emprego e no retorno ao emprego;

f) Promover oportunidades de trabalho autônomo, empreendedorismo, desenvolvimento de cooperativas e estabelecimento de negócio próprio;

g) Empregar pessoas com deficiência no setor público;

h) Promover o emprego de pessoas com deficiência no setor privado, mediante políticas e medidas apropriadas, que poderão incluir programas de ação afirmativa, incentivos e outras medidas;

i) Assegurar que adaptações razoáveis sejam feitas para pessoas com deficiência no local de trabalho; trabalho;

j) Promover a aquisição de experiência de trabalho por pessoas com deficiência no mercado aberto de

k) Promover reabilitação profissional, manutenção do emprego e programas de retorno ao trabalho para pessoas com deficiência.

2.Os Estados Partes assegurarão que as pessoas com deficiência não serão mantidas em escravidão ou servidão e que serão protegidas, em igualdade de condições com as demais pessoas, contra o trabalho forçado ou compulsório. 
Paralelamente a essa abordagem quanto aos modelos conceituais acerca das pessoas com deficiência, bastante pertinente uma breve digressão sobre os termos que ao longo dos anos têm sido utilizados para designá-las, os quais sinalizam, em última instância, retrocessos ou avanços no tratamento jurídico e político dessa questão.

Com efeito, as pessoas com deficiência foram designadas ainda no início século XX, tanto na literatura, nas instituições públicas e nos diplomas legais, como "inválidas", o que lhes estigmatizava como "indivíduos sem valor”, socialmente inúteis, fardos para suas famílias. No período pós-guerra, passou-se a empregar o termo "incapacitados", o que não deixou de representar um avanço, na medida em que compreendia-se que as pessoas assim denominadas detinham capacidade residual para algumas práticas da vida (SASSAKI, 2003, p. 12-15).

De 1960 a 1980, verifica-se a inserção do vocábulo "defeituosos", "deficientes" ou "excepcionais", que focalizam as deficiências em si, sem reforçarem o que as pessoas não conseguiam fazer como a maioria (SASSAKI, 2003, p. 12-15). A partir de 1981, quando se popularizaram os termos utilizados pela Organização Mundial de Saúde, na Classificação Internacional de Impedimentos, Deficiências e Incapacidades, nunca mais se utilizou a palavra "indivíduo" para denominar as pessoas com deficiência, utilizando-se em seu lugar, a palavra "pessoa", igualando-os em dignidade às pessoas sem deficiência (SASSAKI, 2003, p. 12-15). O termo "pessoa deficiente", porém, passou a ser criticado, pois representava que a pessoa inteira seria deficiente, cedendo lugar à expressão "pessoa portadora de deficiência" (SASSAKI, 2003, p. 12-15).

Da década de 90 até hoje, preferiu-se trocar o termo "deficiência” por "necessidades especiais", o qual também foi alvo de críticas, pois “portar" não seria a expressão adequada para algo que não pode ser deixado pela pessoa que o porta. A partir da Declaração de Salamanca, de 1994, empregou-se definitivamente o termo que melhor traduz as li mitações vividas por essas pessoas, sem lhes retirar a dignidade humana: pessoas com deficiência. Trata-se de expressão que enfatiza mais a pessoa do que sua deficiência, de modo que, apesar de suas limitações, não deixa de ser pessoa, com direitos à inclusão social (SASSAKI, 2003, p. $12-15)$. 


\section{A PROTEÇÃO dAS PESSOAS COM DEFICIÊNCIA - EVOLUÇÃo NORMATIVA INTERNACIONAL E RECEPÇÃO NO ORDENAMENTO JURÍDICO BRASILEIRO}

A segregação da pessoa com deficiência é fato histórico, aferível a partir da investigação perfunctória do regramento normativo precedente às leis que atualmente compõem o arcabouço jurídico de seus direitos e garantias.

Historicamente, as informações sobre pessoa com deficiência estão contidas de forma esparsa, na literatura grega e romana, na Bíblia, no Talmud e no Corão (ARANHA apud GURGEL, 2006, p.20). Na Grécia antiga, os espartanos eliminavam aqueles que nasciam com algum defeito físico visível; os romanos abandonavam as crianças deformadas e filhos havidos fora do casamento. Platão, na "República", recomendava esconder os disformes e Aristóteles, na "Política" orientava que nenhuma criança nascida disforme merecia ser “criada” (PEREIRA; KURY apud GURGEL, 2006, p. 20).

O desenvolvimento filosófico e das ciências naturais ocorrido nos séculos XVII e XVIII contribuíram para o avanço da compreensão social a respeito das deficiências, fazendo surgir, por exemplo, as primeiras iniciativas de ensino de comunicação para pessoas surdas e as sementes das instituições especializadas em tratamento de deficiências mentais. Data desse período o surgimento do código Braile, por Louis Braille e aprimoram-se a cadeira de roda, bengalas, muletas, próteses entre outros instrumentos de apoio (GURGEL, 2006, p. 21).

Apesar de toda essa evolução, a preocupação da comunidade jurídica internacional com a efetiva proteção dos direitos das pessoas com deficiência somente começou a ganhar corpo após a ocorrência das duas Guerras Mundiais (1914-1918 e 1939-

1945) e, posteriormente, Guerra do Vietnã (1955-1975), quando passou a ser alarmante o número de vítimas acometidas de deficiência auditiva, visual e de locomoção.

No Brasil, o saldo desastroso das guerras não chegou a atingir um número significativo de pessoas, de modo a deflagrar ações afirmativas nacionais de proteção às pessoas com deficiência. A rigor, as causas da deficiência, no país, de devem aos acidentes de trânsito, à carência alimentar, à dificuldade de acesso a tratamentos preventivos e às precárias condições de higiene (ARAÚJO, 2011, p. 8). 
A proteção das pessoas com deficiência nunca foi objeto de preocupação do constituinte brasileiro desde 1824 a 1969. Não obstante a comunidade internacional já estivesse mobilizada em torno do tema - como revela a publicação da Declaração dos Direitos dos Deficientes Mentais, 1971, pela ONU - o ordenamento jurídico brasileiro passou a contemplar apenas a tímida previsão constante da Emenda Constitucional $n^{\circ} 1$, de 1969, cujo texto não foi sequer incorporado ao corpo da Constituição, permanecendo ao final desta, deixando entrever a segregação normativa a que eram submetidos os direitos das pessoas com deficiência nessa época.

Em 1975, a Assembleia Geral das Nações Unidas, com o objetivo de promover níveis de vida mais elevados, trabalho permanente para todos, condições de progresso, desenvolvimento econômico e social, formula a Declaração dos Direitos das Pessoas Portadoras de Deficiência, tendo em vista a necessidade de prevenir deficiências físicas e mentais e de prestar assistência às pessoas deficientes para que elas possam desenvolver suas habilidades nos mais variados campos de atividades e para promover, portanto, quanto possível, sua integração na vida normal (GURGEL, 2006, p. 27).

Esse marco normativo serviu de referência para a elaboração da Emenda Constitucional $n^{\circ} 12 / 78$ que passa a empregar o termo "deficiente", assegurando-lhe a implementação de melhores condições sociais e econômicas, por meio da educação especial e gratuita; assistência, reabilitação e reinserção na vida econômica e social do país; proibição de discriminação, inclusive quanto à admissão ao trabalho ou ao serviço público e a salários e possibilidade de acesso a edifícios e logradouros públicos.

Percebida a grave questão social em torno das pessoas com deficiência, a comunidade internacional passou a debruçar-se mais detidamente sobre o problema e a agregar esforços às iniciativas políticas dirigidas a sua solução.

Em 1980, a Organização Mundial de Saúde pública a Classificação Internacional de Impedimentos, Deficiências e Incapacidades - CIDID (Internacional Classification of Impairments, Disabilities anda Handicaps - ICIDH). Em seguida, as Nações Unidas proclamaram 1981 como o Ano Internacional das Pessoas Deficientes (ONU, Resolução n o. 34/154, 1979), movimento que ganhou força em 1982, com o lançamento do Programa de Ação Mundial para as Pessoas com Deficiência (ONU, Resolução nº. 37/52 - World Programme of Action Cocerning Disabled Persons). Esse movimento repercutiu também no âmbito da Organização Internacional do Trabalho (OIT), em 1983, que fez publicar a Convenção nº 159 , 
acerca da Reabilitação Profissional e Emprego das Pessoas Deficientes. Imerso na onda gerada pela atuação internacional em prol das pessoas com deficiência, o Brasil fez introduzir, na Constituição de 1988 a designação de pessoa portadora de deficiência, vindo a ratificar posteriormente a citada Convenção da OIT $n^{\circ}$. 159 , publicada pelo Decreto Legislativo nº 129 de 22 de maio de 1991.

No contexto mundial de luta pela inclusão dos direitos das pessoas com deficiência nos ordenamentos jurídicos locais e sua efetivação, merecem registro as Normas sobre a Equiparação de Oportunidades para Pessoas Portadoras de Deficiência (ONU, Resolução no. 48/96, 1993), Declaração de Salamanca, de junho de 1994, sobre o direito à educação às pessoas com deficiência; Carta para o Terceiro Milênio da Reabilitação Internacional, de setembro de 1999, para garantir a plena inclusão da pessoa com deficiência na sociedade; Declaração de Washington, de setembro de 1999; Declaração de Montreal de junho de 2001, que estimula a adoção do desenho inclusivo em todos os ambientes, produtos e serviços; Declaração de Madri, de março de 2002; Declaração de Sapporo e Declaração de Caracas, ambas de outubro de 2002 (GURGEL, 2006, p. 29-30).

Analisando o contexto histórico precedente, em cotejo com esses marcos normativos internacionais, consoante mencionado em tópico acima, Piovesan (2013, p. 268) divide em quatro fases históricas a evolução dos direitos humanos das pessoas com deficiência: primeira fase de completa intolerância, em que a deficiência era concebida como impureza ou castigo divino; segunda fase, marcada pela indiferença, como se invisíveis fossem; terceira fase, identificada com o modelo médico, como se a deficiência fosse algo a ser curado; quarta fase, cuja diretriz é compreender a deficiência sob o prisma dos direitos humanos, sendo dever do Estado e da sociedade eliminar as barreiras que se impunham à real concretização dos direitos das pessoas com deficiência.

É nessa última fase em que se insere a Convenção Internacional sobre os Direitos das Pessoas com Deficiência e seu Protocolo Facultativo, doravante denominada "Convenção de Nova Iorque", adotada pela Organização das Nações Unidas, de acordo com a Resolução $n^{\text {o }}$ 61/106 da Assembleia Geral. Foi o primeiro tratado de direitos humanos do século XXI e o que teve as negociações mais céleres já registradas. A Convenção e seu Protocolo Facultativo, assinados em Nova York, em 30 de março de 2007, foi ratificada pelo Brasil, tendo seu instrumento depositado junto ao Secretário-Geral das Nações Unidas em $1^{\circ}$ de agosto de 2008 (PRESIDÊNCIA DA REPÚBLICA, 2008) 
Importante destacar, nesse ponto, que a Constituição Federal de 1988, desde o texto original, já previa (artigo $5^{\circ}, \S 2^{\circ}$ ) que os direitos e garantias nela expressos não excluíam outros decorrentes do regime e dos princípios por ela adotados, ou dos tratados internacionais em que a República Federativa do Brasil fosse parte.

Avanço de inigualável valia para superar as divergências doutrinárias e jurisprudenciais sobre a posição hierárquico-normativa dos tratados internacionais de direitos

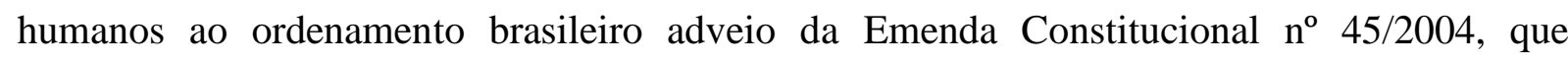
acrescentou o $\S 3^{\circ}$ ao artigo $5^{\circ}$ supramencionado. A partir de então, os tratados e convenções internacionais sobre direitos humanos que fossem aprovados, em cada Casa do Congresso Nacional, em dois turnos, por três quintos dos votos dos respectivos membros, seriam equivalentes às emendas constitucionais, o que significa aplicação imediata e eficácia plena desses direitos, conforme assegura o $§ 1^{\circ}$ do mesmo preceptivo.

A Convenção de Nova Iorque foi o primeiro tratado internacional a ser aprovado com esse quórum qualificado, tendo sido publicado o Decreto 186/2008, no Diário Oficial da União de 10 de julho de 2008. Entrou em vigor para o Brasil, no plano jurídico externo, em 31 de agosto de 2008 e, internamente na condição de emenda constitucional, a partir do Decreto $n^{\circ} 6.949$, publicado em 26 de agosto de 2009.

\section{REALIDADE BRASILEIRA ATUAL}

Não obstante toda a evolução legislativa que conduziu progressivamente à ampliação dos horizontes políticos e jurídicos acerca da questão das pessoas com deficiência, o exame minudente da realidade conduz à inquietante constatação de que se faz necessária a efetiva concretização dos direitos já reconhecidos.

Atualmente, conforme Cartilha do Censo 2010 - Pessoas com Deficiência (IBGE, 2012), há no país mais de 45 milhões de brasileiros, cerca de 23,9\% da população nacional, que possuem algum tipo de deficiência (visual, motora, auditiva, mental ou intelectual). Observa-se, pelos dados ali demonstrados, que, não obstante os avanços legislativos, ainda há muito o que se construir em prol da concretização de direitos sociais básicos, que implementariam a desejada inclusão social das pessoas com deficiência, principalmente nos quesitos educação e trabalho. 
As pessoas com deficiência apresentaram taxas de alfabetização menores do que a população total em todas as regiões brasileiras. Os maiores desníveis - considerando a comparação entre pessoas com pelo menos uma deficiência e pessoas sem deficiência - foram encontrados na investigação dos índices de instrução: no universo de pessoas com 15 anos ou mais, que atingiram determinados anos de estudo, 38\% das pessoas sem deficiência não possuem qualquer instrução ou possuem somente o ensino fundamental incompleto, índice pequeno quando comparado aos $61,1 \%$ das pessoas com deficiência. Em relação ao trabalho, considerando as pessoas com deficiência em idade economicamente ativa (entre 15 e 69 anos), somente $54.8 \%$ delas encontram-se ocupadas (trabalhando formalmente), índice pelo menos $10 \%$ menor do que a taxa de ocupação das pessoas sem deficiência, na mesma faixa etária.

Essa análise detalhada da realidade brasileira conduz à inquietante conclusão de que ainda há um longo caminho a ser percorrido até que se vençam as barreiras que se impõem à efetiva concretização dos direitos das pessoas com deficiência no país.

\section{O DIREITO AO TRABALHO POR PARTE DAS PESSOAS COM DEFICIÊNCIA - O ACESSO AO CARGO PÚBLICO E SEU EFETIVO EXERCÍCIO}

Sobre o direito ao trabalho, os Estados signatários da Convenção de Nova Iorque devem reconhecer o direito das pessoas com deficiência ao trabalho, em igualdade de oportunidades com as demais pessoas. Esse direito abrange o direito à oportunidade de se manter com um trabalho de sua livre escolha ou aceitação no mercado laboral, em ambiente de trabalho que seja aberto, inclusivo e acessível a pessoas com deficiência (artigo 27 da Convenção de Nova Iorque). Os Estados Partes deverão ainda salvaguardar e promover a realização do direito ao trabalho, inclusive daqueles que tiverem adquirido uma deficiência no emprego, adotando medidas apropriadas, incluídas na legislação, com o fim de, entre outros empregar pessoas com deficiência no setor público.

Dando cumprimento a esse comando, Constituição Federal, em seu artigo 37, inciso VIII, determina que a lei reserve percentual de cargos e empregos públicos para pessoas com deficiência.

Durante anos, as pessoas com deficiência empreenderam verdadeira jornada rumos aos tribunais a fim de garantir, via Poder Judiciário, direito que lhes fora assegurado 
constitucionalmente, por meio do preceptivo constitucional supracitado, associado ao direito de acesso aos cargos públicos e à investidura via concurso público, consignados nos incisos I e II do mesmo artigo.

Após superada essa primeira barreira - a entrada no serviço público, via percentual de vagas assegurado por lei, o que ainda encontra obstáculos em algumas unidades federativas, mormente nos municípios, diante da ausência de lei definidora do percentual correspondente - cumpre caminhar rumo à concretização do direito ao efetivo exercício das funções inerentes ao cargo então ocupado.

Em outras palavras, muito embora as pessoas com deficiência tenham alcançado importante conquista (a reserva de vaga para o ingresso nos quadros públicos), muitas vezes o exercício das atribuições do cargo para o qual são nomeadas resta bastante prejudicado, tendo em vista a ausência ou inadequação da estrutura suficiente para tanto. Além disso, como desdobramento do primeiro problema, não se pode deixar de mencionar a questão da deficiência superveniente ao ingresso na instituição pública.

A Convenção de Nova Iorque possui instrumental normativo que se presta a solucionar essas questões: ela determina, em seu artigo 27, alínea "k", promover reabilitação profissional, manutenção do emprego e programas de retorno ao trabalho para pessoas com deficiência. Ademais, no artigo 27, alínea “i”, assegura às pessoas com deficiência que sejam fornecidas adaptações necessárias e razoáveis para que possam exercer suas atribuições legais. Comando semelhante, porém mais específico e incisivo, consta do artigo $34, \S 1^{\circ}$ da Lei $n^{\circ} 13.146 / 2015$, segundo o qual as pessoas jurídicas de direito público, privado ou de qualquer natureza são obrigadas a garantir ambientes de trabalho acessíveis e inclusivos.

Cumpre investigar, portanto, se a legislação nacional, pertinente aos órgãos e carreiras públicas, dispõe de mecanismos para amparar o direito do servidor com deficiência a exercer o cargo que ocupa e como as instituições públicas tem resolvido a questão após receber essas pessoas em seus quadros.

Em pesquisa inicial, junto aos sítios eletrônicos dos órgãos da Administração Direta do Estado do Ceará, (Legislativo, Executivo, Judiciário, Ministério Público, Defensoria Pública, dentre outros $)^{8}$ não se logrou encontrar qualquer estatística acerca da quantidade de pessoas com deficiência investidas nos respectivos cargos públicos ou que tipo de deficiência possuem,

\footnotetext{
8 Consultar: http://www.al.ce.gov.br/, http://www.ceara.gov.br/, http://www.tjce.jus.br/principal/default.asp, http://www.mpce.mp.br/, http://www.defensoria.ce.gov.br/
} 
tampouco há referências acerca de seus processos de adaptação funcional e adequação às atribuições assumidas. É bem verdade que se poderia cogitar buscar esse dado por meio da sistemática fornecida pelas leis de acesso à informação, contudo é possível que esse fato revele algo mais preocupante: na condição de minoria, os servidores com deficiência não são contabilizados com destaque nas estatísticas do órgão.

Quanto à legislação respectiva, constatou-se que, muito embora a previsão da reserva legal de vagas às pessoas com deficiência seja uma constante, o direito das pessoas com deficiência, aprovadas em concurso público, ao pleno exercício das atribuições legais inerentes ao cargo encontra-se carente da mesma atenção.

Merece registro, por exemplo, o Estatuto dos Servidores Públicos Estaduais do Ceará, Lei Estadual no 9.628 de 14 de maio de 1974, em não se verifica qualquer menção a servidor público com deficiência, a não ser pelo seu artigo 250 que prevê a readaptação do servidor com capacidade laboral reduzida, cujo procedimento se reporta a institutos não recepcionados pela atual ordem constitucional - transferência e ascensão funcional.

A legislação estadual que rege as carreiras jurídicas mais proeminentes no cenário nacional - Magistratura Estadual, Ministério Público Estadual e Defensoria Pública também ressentem-se de igual previsão. Trata-se da Lei Complementar no 72/2008 (Lei Orgânica do Ministério Público do Estado do Ceará), da Lei Estadual n n 12.342/1994 e alterações posteriores (Código de Organização Judiciária do Estado do Ceará), e da Lei Complementar nº 06/1997 (Lei Orgânica da Defensoria Pública do Estado do Ceará).

Não obstante esteja longe de representar o que realmente se esperava da legislação regulamentadora das carreiras públicas, no sentido de prever condições diferenciadas de trabalho ao servidor com deficiência física, a Lei ${ }^{\circ} 8.112 / 90$ passou a estabelecer em seu artigo $98, \S 2^{\circ}$, após alteração pela Lei $\mathrm{n}^{\circ} 9.527 / 97$, a concessão de horário especial ao servidor "portador de deficiência", quando comprovada a necessidade por junta médica oficial, independentemente de compensação de horário, benefício extensivo ao servidor que tenha cônjuge, filho ou dependente com deficiência.

Em uma análise perfunctória do problema, a solução mais fácil parece ser adaptar as atribuições do cargo às limitações da pessoa. É nesse sentido que a Lei no 8.112/90 prevê o instituto da readaptação, em seu artigo 24 , segundo o qual o servidor que sofrer limitações em sua capacidade física ou mental será investido em cargo de atribuições e responsabilidades 
compatíveis, verificada em inspeção médica. A mencionada lei ainda determina que se julgado incapaz para o serviço público, o readaptando será aposentado.

A maioria da doutrina administrativista brasileira ${ }^{9}$, ao comentar o instituto de que ora se cuida, apenas o inclui como uma das formas de provimento derivado horizontal de cargo ou emprego público, sem, no entanto, debruçar-se sobre o aspecto constitucional da matéria, principalmente sob as novas luzes dadas pela Convenção de Nova Iorque e pela Lei $n^{\circ} 13.146 / 2015$.

De fato, a readaptação não deve ser manejada como burla à regra do concurso público - à semelhança de institutos já retirados do ordenamento jurídico brasileiro, tais como a transferência e a ascensão - mas como uma última tentativa da Administração de aproveitar as capacidades laborativas do servidor que possui maiores restrições físicas ou mentais, impostas por problemas de saúde.

Neste ponto, importante frisar que há uma distinção entre a situação dos servidores com deficiência (seja ela existente antes ou depois do ingresso nos quadros públicos) e a dos servidores que simplesmente encontram-se acometidos de alguma doença que os tenha incapacitado temporariamente. E é essa distinção que deve marcar o tratamento destinado ao servidor acometido de doença ou moléstia que o tenha incapacitado (ainda que temporariamente) daquele servidor com deficiência, de modo que a readaptação não se mostra como a solução adequada para solucionar o problema de que ora se cuida.

Quando uma pessoa com deficiência visual ou auditiva, por exemplo, ingressa por concurso no serviço público, a Administração deve fornecer o instrumental necessário para que ela exerça as atribuições do cargo que está ocupando e não "readaptá-la" para outra função inferior. O mesmo raciocínio vale quando o servidor, por qualquer motivo, passa para a condição de pessoa com deficiência: a Administração não deve proceder (pelo menos, não de imediato) à sua readaptação.

Isso porque a Convenção de Nova Iorque, artigo 27, alínea “i”" (válida no Brasil na condição de Emenda Constitucional) assegura às pessoas com deficiência que sejam fornecidas adaptações necessárias e razoáveis para que possam exercer suas atribuições legais e não o contrário.

\footnotetext{
${ }^{9}$ Por exemplo, MELLO, 2010. p. 311
} 
Readaptar, na maioria dos casos, significa designar o servidor para que exerça atribuições inferiores, menos complexas o que, em análise mais detida, pode significar exclusão da pessoa com deficiência, contrariando o movimento internacional, ao qual o país aderiu, de inclusão dessas pessoas em todos os ambientes sociais.

Na maioria das situações, subtrair atribuições inerente a determinado cargo, por força das limitações vividas pelo seu ocupante afeta-lhe a dignidade, na medida em que representa, em última instância, discriminação baseada na deficiência. Seria esvaziar de sentido o direito de acesso aos cargos públicos previsto pela Constituição Federal, Convenção de Nova Iorque e agora pela Lei $n^{\circ} 13.146 / 2015$.

Nesse contexto, o servidor com deficiência, ocupante de determinado cargo público, que resta impedido de exercer suas atribuições legais - para além do prejuízo individual - deixa uma lacuna na prestação do serviço público a ser devolvido à sociedade que, como é de comezinha sabença, verte um preço altíssimo para subsidiá-la. Cuida-se, pois, de ofensa ao direito da pessoa com deficiência, de graves repercussões para a Administração Pública em geral.

Assim, conclui-se que o instituto da readaptação, na maior parte das situações em que for empregado para solucionar problemas pertinentes às limitações de servidores com deficiência, estará contrariando a Convenção de Nova Iorque, que alçada à categoria de Emenda Constitucional, ensejará o vício da inconstitucionalidade.

O que se espera, portanto, da Administração é que verta esforços no sentido de fornecer ao servidor com deficiência o aparato necessário ao exercício das funções de seu cargo e não de um mais "simples" ou inferior ao seu. A readaptação serve, portanto, via de regra, para solucionar limitações temporárias, decorrentes de problemas de saúde, precedida de licença médica. É possível que, em casos pontuais, a Administração dela se valha como último recurso, porém, nunca poderá ser utilizado sem antes haver ações inclusivas dirigidas a preservar a igualdade de condições de trabalho entre servidores com e sem deficiência.

\section{CONCLUSÃO}

Para quem está inserido no universo das minorias, não há conceito mais acertado do que aquele defendido por Rudolf Von Ihering, ao afirmar que o direito é luta (IHERING, 2009, p. 22). E se há verdade nessa assertiva, conclui-se que cada avanço legislativo no 
sentido de reconhecer os direitos das pessoas com deficiências, inserindo-os, de início, na ordem jurídica internacional e, posteriormente, nas legislações internas, encerra uma importante vitória na luta das pessoas com deficiência.

Entretanto, a reserva de vagas em concursos públicos, apesar de configurar destacado avanço na referida luta pela igualdade, não se mostra suficiente para garantir às pessoas com deficiência o efetivo exercício das atribuições do cargo, direito assegurado pela Convenção de Nova Iorque e, agora, também pela nova Lei nº 13.146/2015.

Com efeito, examinando a legislação estadual (tomou-se, por amostra a legislação vigente no estado do Ceará) e federal, não se verificou a presença de normatização específica sobre a matéria, a não ser a já bastante citada reserva de vaga. A legislação realmente ressente-se de institutos que, de fato, obriguem a Administração a prover o servidor com deficiência do instrumental necessário ao exercício das funções de seu cargo.

Essa conclusão - além de incentivar que sejam examinadas outras legislações estaduais em busca de transformar soluções pontuais em soluções gerais - revela a necessidade de marcos normativos que confiram caráter nacional ao tema, impelindo a Administração de cuidar para que os candidatos com deficiência, aprovados em concurso público, venham de fato a exercer suas funções e não funções mais simples ou inferiores do que aquelas inerentes ao cargo ocupado.

É por essa razão que o instituto da readaptação - constante da legislação federal e estadual e, por vezes utilizado para solucionar o problema - não pode ser a primeira saída, sob pena de ofensa à Convenção de Nova Iorque, o que significa afronta à Constituição Federal. De fato, incumbir a pessoa com deficiência de atribuições "inferiores" ou "mais simples", compromete-lhe a dignidade, na medida em que representa, em última instância, discriminação baseada na deficiência.

Trata-se de uma particularidade pertinente ao direito ao trabalho no serviço público, com reflexos no direito constitucional de acesso ao cargo público, o qual, para ser implementado em sua inteireza, carece ainda de muitos esforços - normativos e administrativos os quais tem o seu início marcado pela reflexão detida sobre o tema, conforme se propõe. 


\section{REFERÊNCIAS}

ARAÚJO, L. A. D. A proteção constitucional das pessoas com deficiência. 4. Ed. Brasília: Sicorde, 2011.

BAPTISTA. Fernando Pavan. O Direito das Minorias da Democracia Participativa. Prisma Jurídico, n. 2, p. 195-205, 2003.

BOBBIO, Norberto. O futuro da democracia - uma defesa das regras do jogo. São Paulo: Paz e Terra, 1997.

BRASIL. Decreto Legislativo no 186, de 9 de julho de 2008. Aprova o texto da Convenção sobre os Direitos das Pessoas com Deficiência e de seu Protocolo Facultativo, assinados em Nova York, em 30 de março de 2007. Disponível em:

<http://www.planalto.gov.br/ccivil_03/constituicao/congresso/DLG/DLG-186-2008.htm>. Acesso em: 10 abr. 2014.

Decreto $n^{0}$ 5.296, de 2 de dezembro de 2004. Regulamenta as Leis nos 10.048, de 8 de novembro de 2000, que dá prioridade de atendimento às pessoas que especifica, e 10.098, de 19 de dezembro de 2000, que estabelece normas gerais e critérios básicos para a promoção da acessibilidade das pessoas portadoras de deficiência ou com mobilidade reduzida, e dá 63

Dignidade da pessoa humana e direitos fundamentais na Constituição Federal de 1988. 8. ed. Porto Alegre: Livraria do Advogado, 2010.

GURGEL, Maria Aparecida. Pessoas com deficiência e o direito ao concurso público: reserva de cargos e empregos públicos, administração pública direta e indireta. Goiânia: UCG, 2006.

IBGE. Censo demográfico 2010. Características gerais da população, religião e pessoas com deficiência. Rio de Janeiro: Instituto Brasileiro de Geografia e Estatística, 2012.

IHERING. Rudolf Von. A luta pelo Direito. Tradução: João de Vasconcelos. São Paulo: Martin Claret, 2009.

KURY, Mário da Gama. Política, Aristóteles. 2. ed. 1988, Brasília: Editora UnB, 1988. 
MELLO, Celso Antonio Bandeira de. Eficácia das normas constitucionais sobre justiça social, Revista de Direito Público n. ${ }^{\circ}$ 57/58, p. 236-237, jan/jun., 1981.

. O conteúdo jurídico do principio da igualdade. São Paulo: Ed. Revista dos Tribunais, 1978.

.Curso de Direito Administrativo. 27. ed. São Paulo: Malheiros, 2010.

OLIVEIRA, Marcelo Andrade Cattoni de. Minorias e Democracia no Brasil. Revista do Instituto de Hermenêutica Jurídica: RIHJ, Belo Horizonte, v. 1, n. 4, jan./dez. 2006.

ONU (1948). Declaração Universal dos Direitos Humanos, de 10 de dezembro de 1948.

Disponível em: <http://portal.mj.gov.br/sedh/ct/legis_intern/ddh_bib_inter_universal.htm>. Acesso em: 3 abr. 2014.

PEREIRA, Maria Helena da Rocha. A República, Platão. 8. ed. Lisboa: Fundação Calouste Gulbenkian, 1996.

PIOVESAN, Flávia. Direitos humanos e o direito constitucional internacional. 14 ed. São Paulo: Saraiva, 2013.

PRESIDÊNCIA DA REPÚBLICA. Secretaria Especial dos Direitos Humanos. Coordenadoria Nacional para Integração da Pessoa Portadora de Deficiência - CORDE. A convenção sobre direitos das pessoas com deficiência: versão comentada. Brasília: Corde, 2008.

SASSAKI, Romeu Kazumi. Vida Independente: história, movimento, liderança, conceito, filosofia e fundamentos. São Paulo: RNR, 2003, p. 12-16.

SILVA, José Afonso da. Aplicabilidade das Normas Constitucionais, São Paulo; Ed. Revista dos Tribunais, $2^{\mathrm{a}}$ edição revista e atualizada, 1982.

SILVA, José Afonso da. Curso de direito constitucional positivo. 19 ed. São Paulo: Malheiros, 2003.

SOUZA, Rafael Barreto. Implementação no Brasil do Artigo 12 da Convenção sobre os Direitos das Pessoas com Deficiência: os impactos da constitucionalização do direito à plena 
capacidade jurídica. 2013. 160 f. Dissertação (Mestrado em Direito). Faculdade de Direito, Universidade Federal do Ceará, Fortaleza, 2013. 